\title{
A revised spreading model of the West Philippine Basin
}

Tomohiro Sasaki ${ }^{1}$, Toshitsugu Yamazaki ${ }^{1,2,3^{*}}$ and Osamu Ishizuka ${ }^{2}$

\begin{abstract}
The West Philippine Basin (WPB) occupies the western part of the Philippine Sea (PHS) plate. The WPB is generally considered to have opened from approximately 50 to $30 \mathrm{Ma}$ at the CBF rift; however, the detailed spreading history of the WPB is not yet clear. In particular, the origin and age of the southern subbasin, the Palau Basin, are unknown. To better understand the initiation and early evolution of the Izu-Bonin (Ogasawara)-Mariana arc, knowing the configuration of the PHS plate at that time is necessary. In this study, we examine the spreading history of the WPB using newly acquired three-component magnetic anomaly and swath bathymetry data, as well as existing datasets. In the WPB south of the CBF rift, the observed magnetic anomalies correspond to Chron C16r to C21n (approximately 36 to $46 \mathrm{Ma}$ ). Prevailing models of the WPB reconstruction show a decrease in the spreading rate from 4.4 to $1.8 \mathrm{~cm} /$ year since C18n.2n (approximately $39.5 \mathrm{Ma}$ ). Our research, however, indicates that the change in the spreading rate is not required to correlate the observed magnetic anomalies to the geomagnetic polarity reversal timescale. The age of the spreading cessation in our interpretation, approximately $36 \mathrm{Ma}$, is several million years older than in previous estimates, and the spreading ceased progressively from southeast to northwest along the CBF rift. In the Palau Basin, seafloor fabrics and magnetic lineations trend N-S, which indicates E-W seafloor-spreading. Based on ${ }^{40} \mathrm{Ar} /{ }^{39} \mathrm{Ar}$ age, we suggest that the magnetic lineations correspond to polarity reversals from C18n.1n to C15r (approximately 38.5 to $35 \mathrm{Ma}$ ). The spreading of the Palau Basin may have been coeval with that of the WPB near the CBF rift, although their spreading directions are different.
\end{abstract}

Keywords: Magnetic anomaly; Topography; West Philippine Basin; Palau Basin; Seafloor spreading

\section{Correspondence/Findings Introduction}

The West Philippine Basin (WPB) (Figure 1) occupies the western part of the Philippine Sea (PHS) plate. The WPB is generally considered to have formed by seafloor spreading during approximately 50 to $30 \mathrm{Ma}$, prior to the opening of the Shikoku and Parece Vela Basins; however, partly because of its structural complexity and the scarcity of modern geophysical data in the southern part of the WPB, the exact details of its formation are not yet clear despite a long history of studies (e.g., Hess 1948; Uyeda and Ben-Avraham 1972; Karig 1975; Hilde and Lee 1984; Deschamps and Lallemand 2002; Taylor and Goodliffe 2004). In particular, the southern subbasin,

\footnotetext{
* Correspondence: yamazaki@aori.u-tokyo.ac.jp

${ }^{1}$ Graduate School of Life and Environmental Sciences, University of Tsukuba,

1-1-1 Tennodai, Tsukuba, Ibaraki 305-8572, Japan

${ }^{2}$ Geological Survey of Japan, AIST, 1-1-1 Higashi, Tsukuba, Ibaraki 305-8567,

Japan

Full list of author information is available at the end of the article
}

called the Palau Basin by Taylor and Goodliffe (2004), has been rarely studied, and its origin and age remained unknown. Recently, the initiation and evolution of the Izu-Bonin (Ogasawara)-Mariana arc have attracted considerable interest as a typical example of an oceanic island arc (e.g., Ishizuka et al. 2006a, b). For a better understanding of the evolution of this arc, knowing the configuration of the PHS plate at that time is necessary. Thus, studies on the development history of the WPB are important.

The WPB is bounded on the east side by the KyushuPalau Ridge and the north side by the Oki-Daito Ridge (Figure 1). The WPB is subducting northwestward underneath the Ryukyu-Taiwan-Philippine arcs and controls volcanic activity there (e.g., Sato et al. 2014). The NW-SE trending CBF rift (previously called the Central Basin Fault) in the central part of the WPB is considered to be a fossil spreading axis (e.g., Uyeda and Ben-Avraham 1972; Louden 1976; Fujioka et al. 1999; Deschamps et al. 2002). The depth of the basin ranges from 5,500 to $6,000 \mathrm{~m}$, 


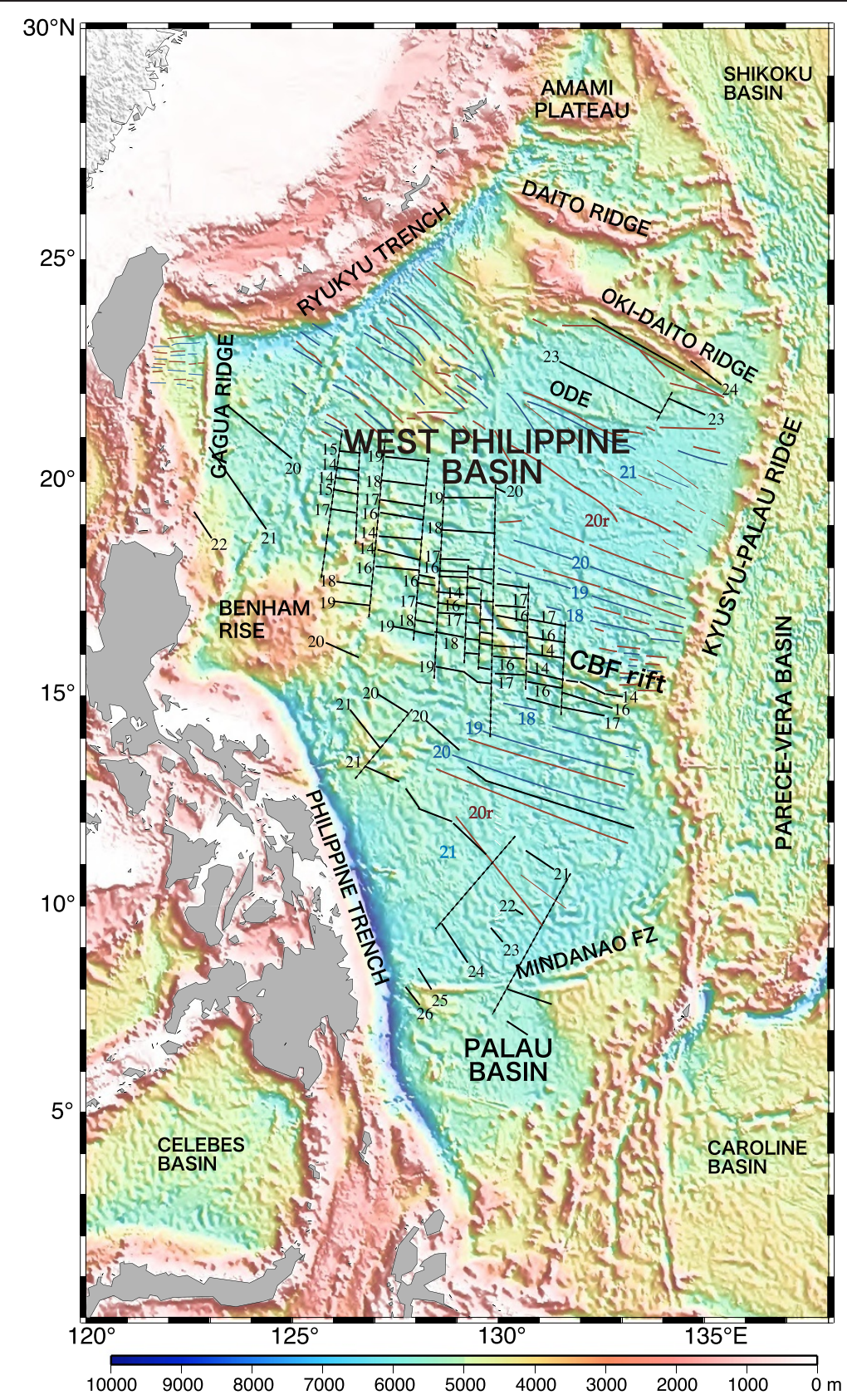

Figure 1 Shaded relief map of the Philippine Sea plate and its vicinity. The gridded topography ETOPO1 derived from satellite altimetry (Sandwell and Smith 1997) was used. Magnetic anomaly lineations are modified after Hilde and Lee (1984) (black) and Taylor and Goodliffe (2004) (brown and blue). ODE, Oki-Daito Escarpment.

which is deeper than the depth expected from the standard age-depth curve, but in accord with the curve derived for back-arc basins (Park et al. 1990). Several attempts have been made to identify magnetic anomalies based on total-force anomalies in the 1970s and 1980s. Louden (1976) and Mrozowski et al. (1982) identified anomalies 21 to 17 (approximately 47 to $37 \mathrm{Ma}$, according to the timescale of Gradstein et al. (2004)). Shih (1980) identified anomaly 7A (approximately $25 \mathrm{Ma}$ ) for the youngest age near the CBF rift, anomaly 21 (approximately $47 \mathrm{Ma}$ ) for the oldest age in the northern part of the WPB, and anomaly 25 (approximately $57 \mathrm{Ma}$ ) for the oldest age in the southern part of the WPB. These authors assumed a constant NE-SW spreading. Hilde and Lee (1984), on the other hand, proposed that the WPB was formed by two phases of spreading: one between anomalies 26 and 19 (approximately 59 to $40 \mathrm{Ma}$ ) in a NE-SW direction at a half-rate of $4.4 \mathrm{~cm} /$ year and another between anomalies 
18 and 13 (approximately 40 to $33 \mathrm{Ma}$ ) in a N-S direction at a rate of $1.8 \mathrm{~cm} /$ year. PHS plate reconstructions (e.g., Hall et al. 1995; Hall 2002; Deschamps and Lallemand 2002) are based on the interpretation of Hilde and Lee (1984), with the exception of the revision made in the region north of the Oki-Daito Escarpment by Deschamps and Lallemand (2002).

The Palau Basin is separated from the main WPB by a fault zone, the Mindanao Fracture Zone (MFZ) (Figure 1). Taylor and Goodliffe (2004) showed that the MFZ is composed of multiple curvilinear strands. The water depth of the Palau Basin floor (approximately 5,500 m) is shallower than in the rest of the WPB north of the MFZ (approximately 5,500 to $6,000 \mathrm{~m}$ ), and the pelagic sediment cover is thicker (Mrozowski et al. 1982). Hilde and Lee (1984) assigned anomalies 26 and 25 (approximately 59 to 56 $\mathrm{Ma}$ ) inside the Palau Basin without considering the presence of the MFZ, which may represent a structural boundary. To date, no radiometric dating of seafloor rocks from the Palau Basin has been reported.

In this study, we compile and analyze bathymetry and magnetic anomaly data collected in the southern part of the WPB over the last decade by the Japan Agency for Marine-Earth Science and Technology (JAMSTEC). Moreover, we include recent data acquired during the $\mathrm{R} / \mathrm{V}$ Yokosuka YK10-14 cruise in 2010. We reexamine magnetic lineations in the WPB, including the Palau Basin, taking the advantage of using a shipboard three-component magnetometer (STCM) (Isezaki 1986). We then present a revised spreading history of the WPB, including the formation of the Palau Basin.

\section{Data and methods}

Bathymetric and magnetic data were collected mainly in the Palau Basin during the R/V Yokosuka YK10-14 cruise. We also used datasets available at the JAMSTEC data portal (http://www.godac.jamstec.go.jp/dataportal/), which mainly consists of data obtained by R/V Mirai between 2000 and 2010 (see Additional file 1 for the list of used datasets). SeaBeam 2112 multi-narrow-beam echo sounders were used for bathymetry on all cruises. For magnetic anomaly measurements, STCMs with ring-laser gyros were used during the YK10-14 cruise and for the datasets of the R/V Mirai cruises. A towed proton magnetometer was also employed during the YK10-14 cruise.

We basically followed the method of Isezaki (1986) for the measurement and data reduction using STCM. The magnetic anomaly data were subjected to long wavelength variations that are supposed to be caused by diurnal variations of the geomagnetic field as well as changes in the ship's magnetization with time - which we assumed to be constant. To rectify these variations, individual components of the observed magnetic data were filtered with a band-pass filter after removing a linear trend; variations with wavelengths from about 4.5 to 180 $\mathrm{km}$ were passed. Strikes of magnetic boundaries were determined for each survey line based on variation patterns of both vertical and horizontal components and the intensity of spatial differential vectors (ISDV) (Seama et al. 1993). Boundary strikes with uncertainties larger than $20^{\circ}$ or boundaries with deviation from the vertical larger than $20^{\circ}$ were considered unreliable and rejected because they may not be related to two-dimensional structures.

\section{Results}

Swath bathymetry and magnetic anomaly profiles of the north component along survey lines in the WPB between the CBF rift and MFZ are shown in Figure 2, where they are superimposed on a topographic map derived from the satellite altimetry (Sandwell and Smith 1997). The strikes of magnetic boundaries at each peak in ISDV were calculated and are shown on the magnetic anomaly profiles. The trend of abyssal hills is close to E-W near the CBF rift. Toward the south, approaching the MFZ, the trend progressively changes to NW-SE (Figures 2 and 3c, Additional file 2). The strikes of magnetic boundaries support the change of the spreading direction. Magnetic anomaly patterns are well correlated among survey lines (Figures 2 and $3 \mathrm{~b}$ ) and indicate WNW-ESE trending magnetic lineations. At around $10.5^{\circ} \mathrm{N}, 130^{\circ} \mathrm{E}$, the NW-SE magnetic boundary strike (orange bar in Figure 2) is inconsistent with the others; it is instead associated with the change in the orientation of the seafloor fabric (Figure 2, Additional file 2). This may be a consequence of rift propagation, which is known to have frequently occurred in the northern part of the WPB (Deschamps et al. 2008). In the southernmost part of the basin between $8^{\circ}$ and $10^{\circ} \mathrm{N}$, topography displays complex fabrics, and magnetic anomalies do not show coherent variations among survey lines (Figures 2 and 3b,c).

A topographic relief map of the Palau Basin is displayed in Figure 4. Although the Palau Basin is covered with relatively thick sediments, abyssal hills trending N-S to NNW-SSE are well expressed in the central part. When approaching the Philippine Trench to the west, the trend of abyssal hills gradually changes to NNE-SSW. Figure 5 shows the three-component and total-force magnetic anomalies along three E-W survey lines (lines 17, 19, and $21)$. The variations in the east and vertical components are larger than those in the north component, suggesting the presence of nearly N-S striking magnetic lineations. The amplitudes of total-force anomalies are small (Figure 5d), which is consistent with the occurrence of $\mathrm{N}-\mathrm{S}$ striking magnetic lineations in low latitudes. Although the original configuration of the Palau Basin is not known, PHS plate motion models suggest a large clockwise rotation since the Eocene and that the Palau Basin was in low latitudes south of the equator at 


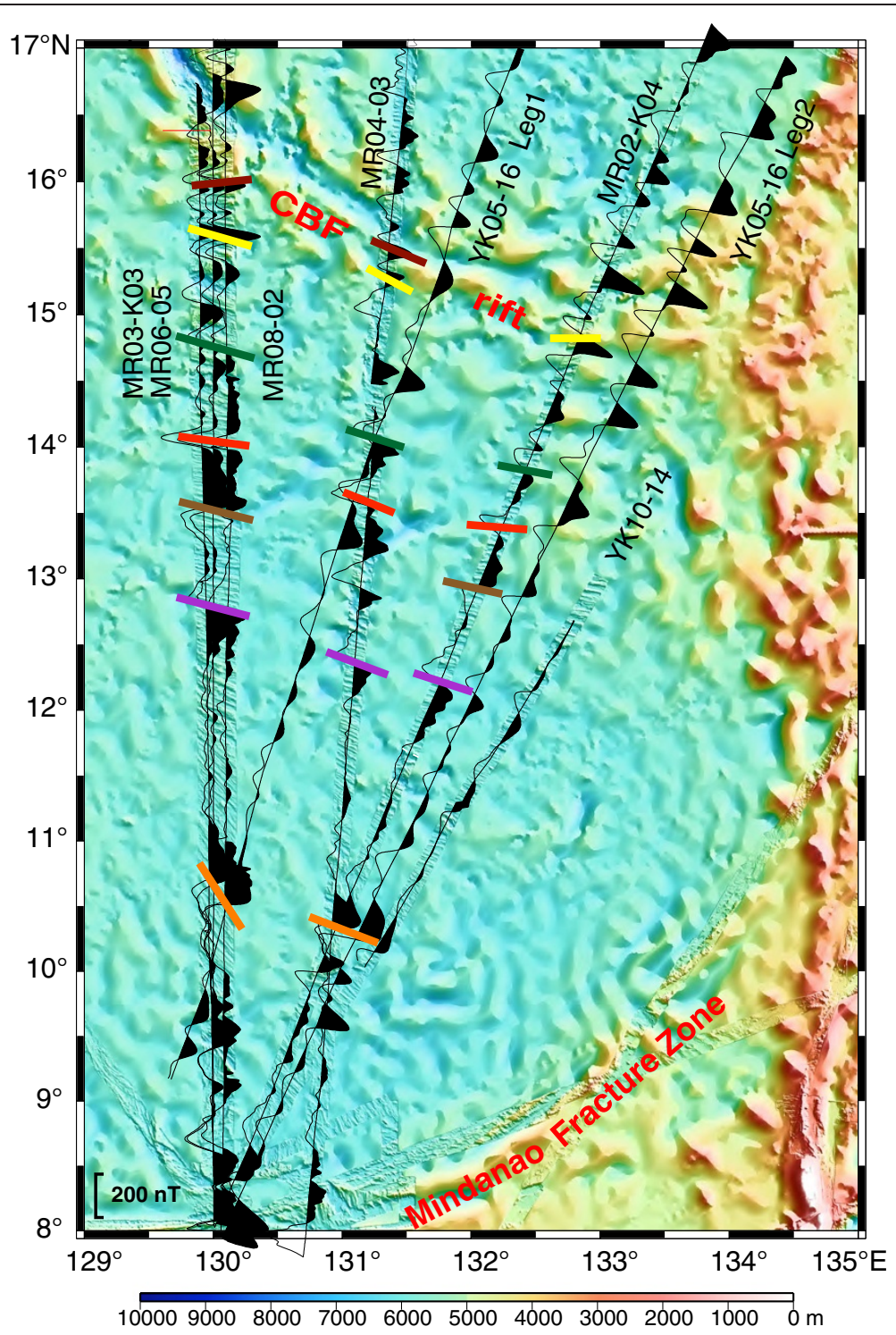

Figure 2 North-component magnetic anomaly profiles in the WPB between the CBF rift and Mindanao Fracture Zone. Magnetic boundary strikes calculated from three-component anomalies are displayed with colored bars. Superimposed are shaded topographic relief based on the ETOPO1 grid and swath bathymetry along survey lines. See Additional file 2 for a shaded relief map without magnetic profiles.

approximately $40 \mathrm{Ma}$ (Hall et al. 1995; Deschamps and Lallemand 2002). Good agreement of anomaly patterns among the survey lines and nearly N-S magnetic boundary strikes also support the occurrence of E-W seafloor spreading.

\section{Magnetic anomaly interpretation \\ Spreading model of the West Philippine Basin south of the CBF rift}

Comparisons between the observed magnetic anomalies and predictions from two-dimensional block models are shown in Figure 3 for the vertical component (see Additional file 3 for the north component). The block models with skewness of approximately $150^{\circ}$ to $180^{\circ}$ fit the observation, which agrees with the findings of previous studies (Louden 1976; Shih 1980; Mrozowski et al. 1982; Hilde and Lee 1984). We tested two spreading scenarios: one assumes a constant spreading rate of 4.4 $\mathrm{cm} /$ year, while the other supposes two-phase spreading as proposed by Hilde and Lee (1984), which is a decrease in the spreading rate from 4.4 to $1.8 \mathrm{~cm} /$ year at the beginning of C18n.2n (39.46 Ma).

Characteristic anomaly patterns between the boundaries of $\mathrm{C} 21 \mathrm{n} / \mathrm{C} 20 \mathrm{r}$ and $\mathrm{C} 19 \mathrm{n} / \mathrm{C} 18 \mathrm{r}$ (45.35 to $40.44 \mathrm{Ma}$ ) are well correlated among all survey lines and agree with the predicted anomalies for the both components. This is consistent with the previous identification of anomalies 21 to 19 (Louden 1976; Shih 1980; Mrozowski et al. 


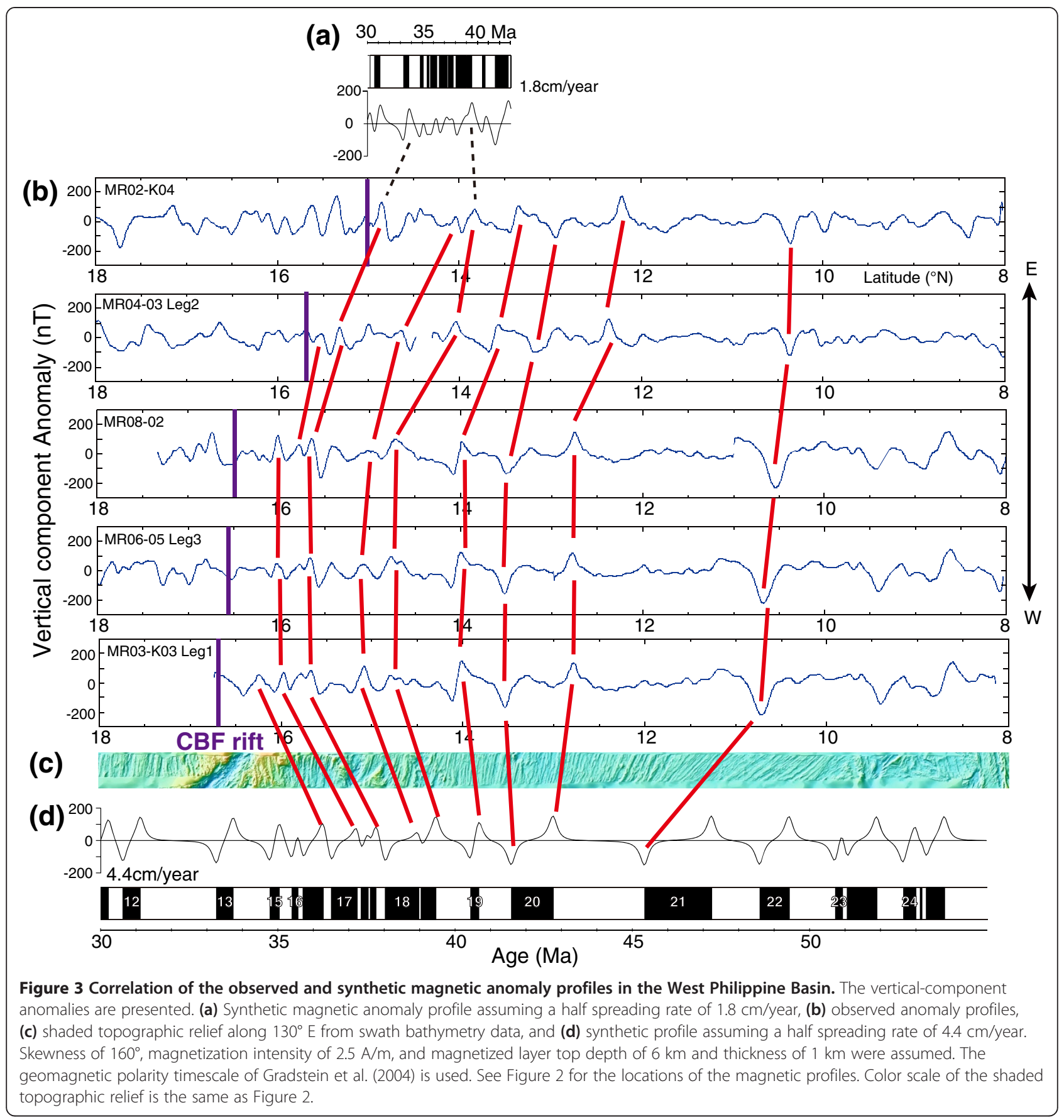

1982; Hilde and Lee 1984). In older areas between approximately $10^{\circ} \mathrm{N}$ and the MFZ, however, correlating the observed and predicted anomalies is difficult, where seafloor fabrics are complex (Figures 3 and 4, Additional file 2). According to the constant spreading model, magnetic polarity reversals between the boundaries of $\mathrm{C} 19 \mathrm{n} /$ $\mathrm{C} 18 \mathrm{r}$ and $\mathrm{C} 17 \mathrm{n} .1 \mathrm{n} / \mathrm{C} 16 \mathrm{r}$ (40.44 to $36.51 \mathrm{Ma}$ ) show good agreement with the observed anomalies between approximately $14.5^{\circ}$ and $16^{\circ} \mathrm{N}$. According to the two-phase spreading model, the observed anomalies may correspond to magnetic polarity reversals between the boundaries of C18r/C18n.2n and C13n/C12r (39.46 to $33.27 \mathrm{Ma}$ ); however, the correlation is ambiguous. Complex seafloor fabrics were observed between approximately $15.5^{\circ}$ and $14.5^{\circ} \mathrm{N}$ along $130^{\circ} \mathrm{E}$ (Figures 2 and 3c). Magnetic anomaly patterns observed over this area are somewhat irregular compared to the areas located to the south and north. According to the constant spreading model, the half 


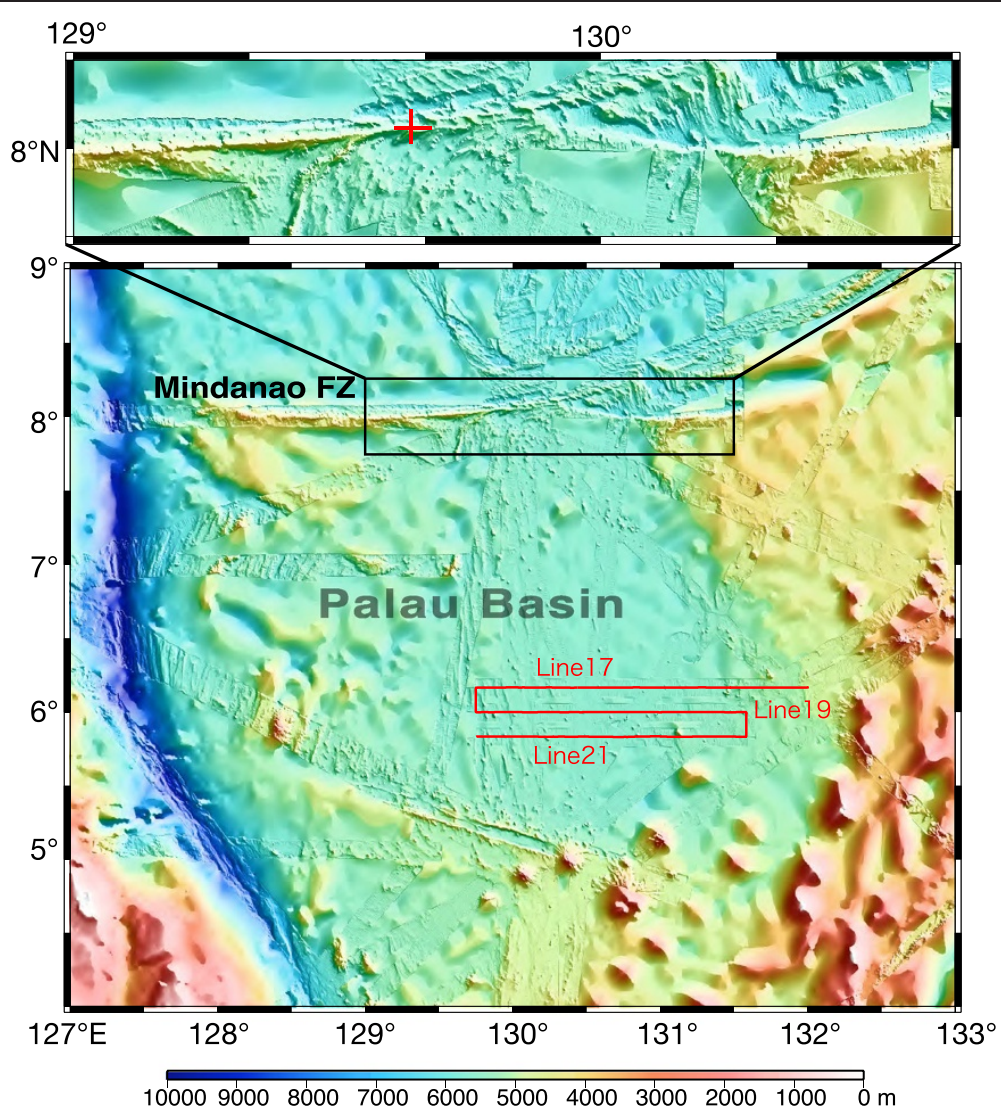

Figure 4 Shaded relief map of the Palau Basin and Mindanao Fracture Zone (MFZ). The ETOPO1 grid and swath bathymetry data along ship tracks were used. The vicinity of the MFZ is enlarged, and a red cross indicates the locality of dated basalt (Ishizuka et al. in prep.). Red lines show survey lines of three-component magnetic anomaly shown in Figure 5.

spreading rate in the studied area is approximately 8 $\mathrm{cm}$ /year at C20r (45.35 to $42.77 \mathrm{Ma}$ ) and approximately $6 \mathrm{~cm} /$ year after the C20n/C20r boundary $(42.77 \mathrm{Ma})$.

\section{Magnetic lineations in the Palau Basin}

Age estimation of the Palau Basin is not straightforward because no radiometric age data is available for basement rocks in the vicinity of the three E-W survey lines. In addition, the length of these lines is insufficient for unique magnetic anomaly identification. Further complexity comes from that we do not know whether the studied area constitutes the eastern or western limb of a spreading center. Ishizuka et al. (in preparation) obtained a radiometric age, 40.4 Ma, from basalt collected at a cliff in the MFZ, where the basement of the Palau Basin is considered to be exposed (Figure 4). We investigated the possibility of temporal correlation with the geomagnetic polarity time scale around $40 \mathrm{Ma}$ because the longitude of the locality of the dated basalt and the western end of the survey lines are almost the same. An $\mathrm{E}-\mathrm{W}$ spreading direction is inferred based on the N-S abyssal hill trend. We examined two cases: the eastern and western limbs of a spreading ridge. In the case of the eastern limb, the observed anomalies in the east and vertical components reasonably fit the predicted anomalies from C18n.1n (approximately $38.5 \mathrm{Ma}$ ) to the end of C15r (approximately $35 \mathrm{Ma}$ ) (Figure 6). This implies a half spreading rate of approximately $4.3 \mathrm{~cm} /$ year, which is slightly slower than that of the WPB. In this model, we adopted skewness of $90^{\circ}$, which was derived from the remanent declination $\left(D_{r}\right)$ and inclination $\left(I_{r}\right)$ of $60^{\circ}$ and $0^{\circ}$, respectively. The $D_{r}$ of $60^{\circ}$ incorporated a large clockwise rotation of the PHS plate since the Eocene (Hall et al. 1995; Deschamps and Lallemand 2002). The ambiguity in $D_{r}$ does not affect the magnetic anomaly interpretation because changes in $D_{r}$ between $30^{\circ}$ and $90^{\circ}$ cause skewness variations of only several degrees. PHS plate motion models suggest that the paleolatitude of the Palau Basin at approximately $40 \mathrm{Ma}$ was between the equator and $10^{\circ} \mathrm{S}$ (Hall et al. 1995; Deschamps and Lallemand 2002). When an $I_{r}$ of $-20^{\circ}$ is adopted, the skewness becomes $110^{\circ}$, which does not significantly affect our interpretation. A skewness of $90^{\circ}$ produces no anomaly in the north component, which is consistent with the observation. In the case of the western limb, no correlation was found. 

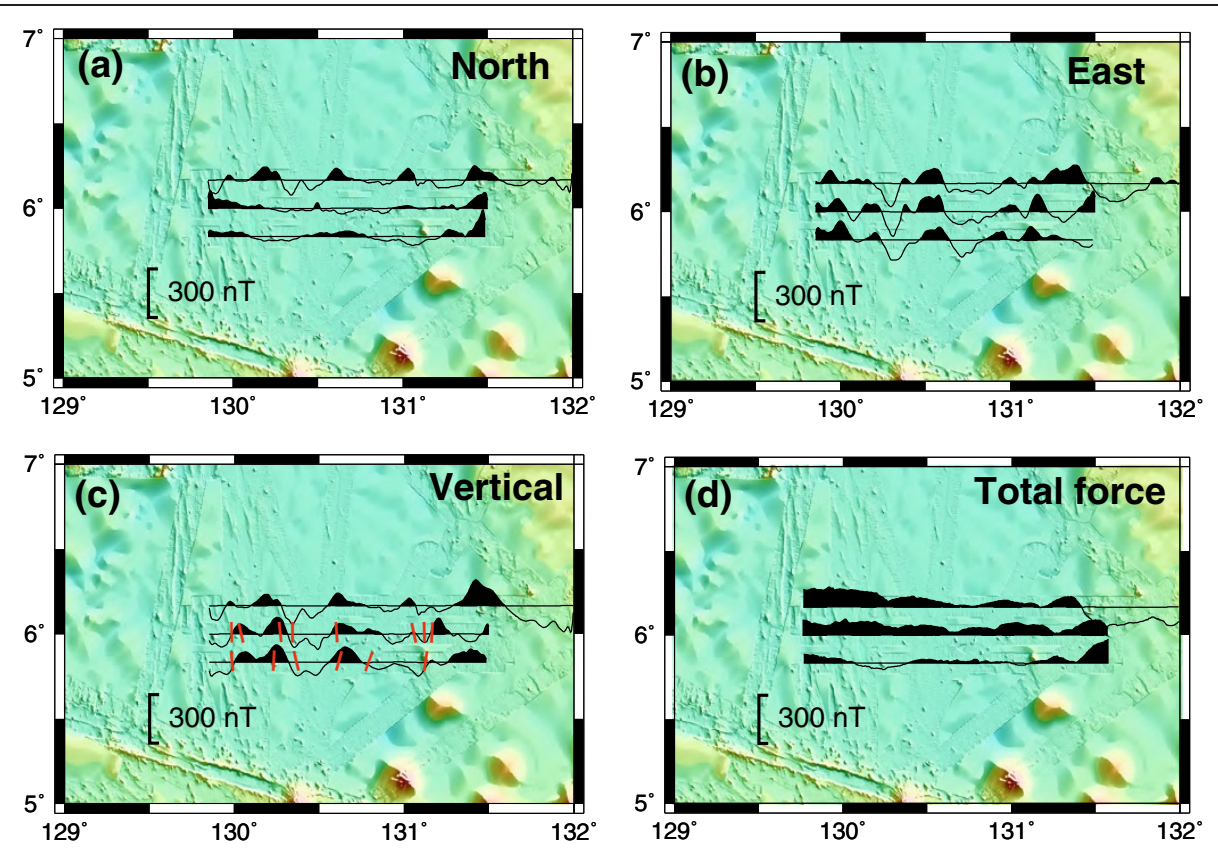

Figure 5 Magnetic anomaly profiles in the Palau Basin. (a) The north, (b) east, and (c) vertical component anomalies and (d) total-force anomalies. Magnetic boundary strikes calculated from the three-component anomalies are shown on (c) (red bar). Shaded relief topography from the ETOPO1 grid and swath bathymetry data along survey lines are superimposed. Color scale is the same as Figure 4.

\section{Discussion}

We have successfully correlated observed magnetic anomalies in the WPB with predictions from the geomagnetic polarity reversal timescale. The three-component magnetic measurements enabled us to identify magnetic lineations more efficiently than total-force measurements. The amplitude of total-force anomaly is reduced in low latitudes depending on the geometry of two-dimensional magnetized bodies, which is not the case in three-component anomalies. In addition, a consistency check among the individual
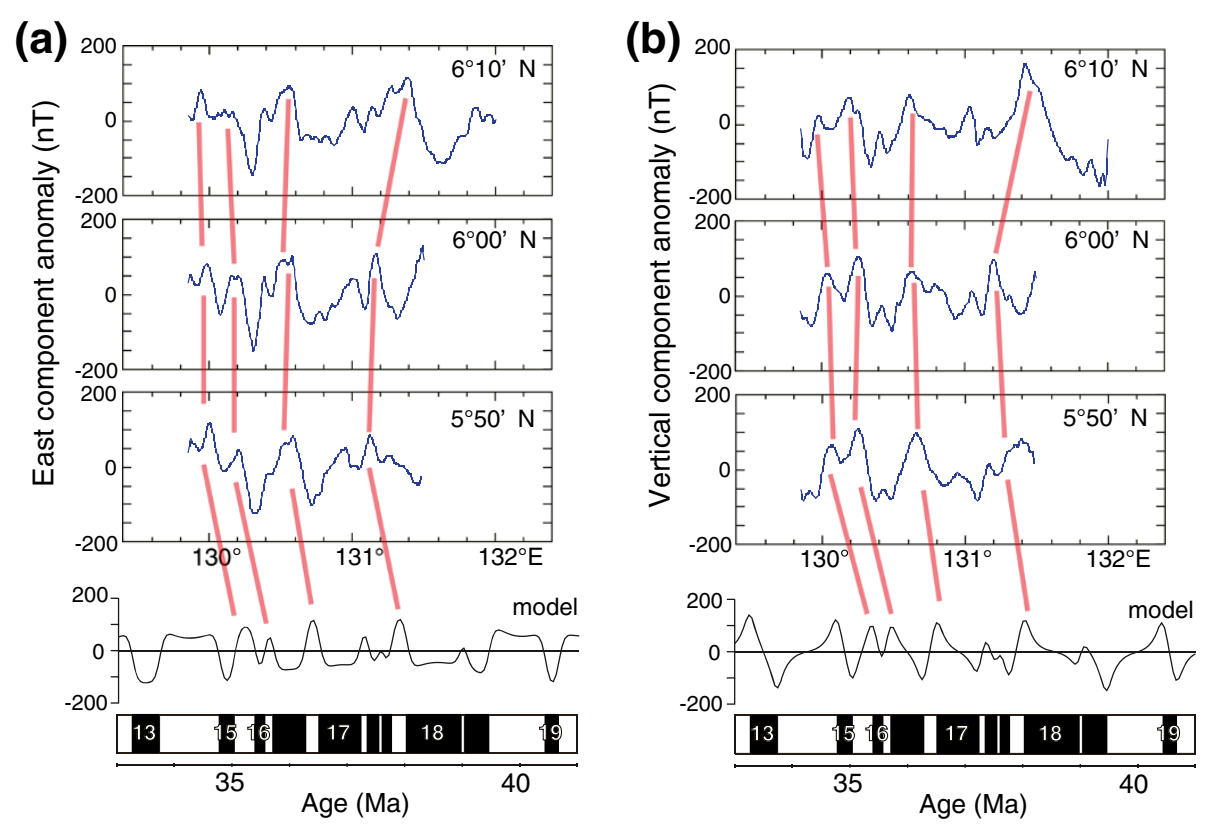

Figure 6 Correlation of the observed and synthetic magnetic anomaly profiles in the Palau Basin. (a) The east-component anomalies and (b) the vertical-component anomalies. Half spreading rate of $4.4 \mathrm{~cm} /$ year, skewness of $90^{\circ}$, magnetization intensity of $2.5 \mathrm{~A} / \mathrm{m}$, and magnetized layer top depth of $6 \mathrm{~km}$ and thickness of $1 \mathrm{~km}$ were assumed. 
components can provide a stronger constraint on magnetic anomaly interpretation than in the case of only total-force anomaly.

Our magnetic lineation identification between the boundaries of $\mathrm{C} 21 \mathrm{n} / \mathrm{C} 20 \mathrm{r}$ and $\mathrm{C} 19 \mathrm{n} / \mathrm{C} 18 \mathrm{r}$ (45.35 to $40.44 \mathrm{Ma}$ ) in the WPB south of the CBF rift is consistent with previous studies based on total-force anomalies (Louden 1976; Shih 1980; Mrozowski et al. 1982; Hilde and Lee 1984). The counter-clockwise topographic fabric change over time is consistent with previous observations along a single line (Andrews 1980; Taylor and Goodliffe 2004) and similar to those described to the north of the CBF rift (Deschamps and Lallemand 2002). Taylor and Goodliffe (2004) suggested that C20r fans southeastward and is much wider compared with its counterpart to the north of the CBF rift due to a ridge jump during C20r. However, the fan shape of C20r observed around $11^{\circ} \mathrm{N}, 130^{\circ} \mathrm{E}$ seems to be a local feature as it does not appear on the adjacent survey lines near $131^{\circ} \mathrm{E}$ (Figure 2). An offset accommodating the difference in spreading directions is inferred to occur between the two regions; thus, invoking the occurrence of a ridge jump is not necessary. Topographic fabrics in the oldest part of the basin, between $10^{\circ} \mathrm{N}$ and the MFZ to the south, are highly disorganized (Figures 2, 3c, and 4 ), and estimating ages based on magnetic anomalies is impossible. This is probably the result of frequent reorganizations of seafloor spreading by means of propagating rifts and overlapping spreading centers during an incipient stage of back-arc basin formation. Tectonic stresses caused by the activity of the MFZ may also be responsible for the complexities.

For magnetic lineation identification, we considered both constant spreading and two-phase spreading. Our results indicate that magnetic anomalies can be well explained without introducing a spreading rate change (Figure 3). In particular, detailed structures within C17 fit remarkably well with the observation based on a constant spreading model; agreement with the model prediction is better than that using a reduced spreading rate of $1.8 \mathrm{~cm} /$ year. As per the data available to them, Hilde and Lee (1984) adopted the two-phase spreading model mainly because they believed that the roughness of the seafloor increases near the CBF rift. This was interpreted as a slower spreading rate. The area between approximately $14.5^{\circ}$ and $15.5^{\circ} \mathrm{N}$ near $130^{\circ} \mathrm{E}$ is such an example; however, this may have been caused by the reorganization associated with slight changes in the spreading direction rather than a slower spreading rate (Deschamps et al. 2002, 2008). Okino and Fujioka (2003) described long-lasting discontinuities extending from the CBF rift to the northern and southern WPB along with pseudo-faults related to eastward ridge propagations. Furthermore, the CBF rift may have been reactivated after the cessation of spreading (Fujioka et al. 1999). Thus, the seafloor roughness near the CBF rift does not necessarily reflect a change in the spreading rate.

According to our results, the cessation of spreading at the CBF rift is estimated to have occurred at approximately $36 \mathrm{Ma}$ near $130^{\circ} \mathrm{E}$, which is older than the $30 / 33$ Ma estimation using the two-phase spreading model (Hilde and Lee 1984; Deschamps and Lallemand 2002). It appears that the spreading ceased progressively from southeast to northwest along the CBF rift; at $15^{\circ} \mathrm{N}$, $133^{\circ} \mathrm{E}$, the cessation occurred at approximately $37.5 \mathrm{Ma}$ (line MR02-K04), and at approximately $35.5 \mathrm{Ma}$ at $16.5^{\circ} \mathrm{N}, 130^{\circ} \mathrm{E}$ (line MR06-05) (Figure 3). The northwestward waning of the spreading is consistent with the hypothesis that the spreading at the CBF rift was triggered by the Oki-Daito mantle plume in the western part of the WPB (Ishizuka et al. 2013). Hilde and Lee (1984) proposed almost uniform cessation ages along the CBF rift; however, even based on such a two-phase spreading model, the cessation was earlier in the eastern part (Figure 3). Volcanic and tectonic activities may have continued until approximately $15 \mathrm{Ma}$ at the CBF rift, which is much later than the cessation of spreading (Fujioka et al. 1999; Deschamps et al. 2002). Similar post-spreading volcanism is known to have occurred at the extinct spreading axis (the Kinan Seamount Chain) after the cessation of spreading in the Shikoku Basin (Ishizuka et al. 2009).

Our results indicate that the Palau Basin was formed by E-W seafloor spreading, between approximately 35 to $39 \mathrm{Ma}$ with a half rate of approximately $4.3 \mathrm{~cm} /$ year, which is slightly slower than that of the WPB. The estimated age of the Palau Basin is close to that of the younger part of the WPB near the CBF rift. This implies that the age of the seafloor just north of the MFZ is considerably older than that of the Palau Basin, which is consistent with the observation that the water depth of the Palau Basin is shallower than in the main part of the WPB. We speculate that the spreading center of the main part of the WPB and that of the Palau Basin were originally parallel and in the N-S direction; the former center then rotated counterclockwise along the MFZ. Our estimated age difference of approximately $5 \mathrm{Ma}$ and average spreading rate of $4.3 \mathrm{~cm} /$ year require left-stepping offsets of about $200 \mathrm{~km}$ in total between the magnetic survey lines at approximately $6^{\circ} \mathrm{N}$ and the MFZ at approximately $8^{\circ} \mathrm{N}$. Due to the sediment cover, identifying any topographic feature that would indicate the occurrence of these offsets is difficult. Further measurements of three-component magnetic anomalies along longer survey lines associated with the dating of basalts are required to confirm our model. 


\section{Additional files}

Additional file 1: Table S1. Datasets used in this study.

Additional file 2: Topographic relief map of the West Philippines

Basin. Shaded topographic relief map of the West Philippine Basin south of the CBF based on the ETOPO1 grid and swath bathymetry along survey lines.

Additional file 3: Correlation of the observed and synthetic magnetic anomaly profiles in the West Philippine Basin: north-component anomalies. (a) Synthetic magnetic anomaly profile assuming a half spreading rate of $1.8 \mathrm{~cm} /$ year, (b) observed anomaly profiles, (c) shaded topographic relief along $130^{\circ} \mathrm{E}$ from swath bathymetry data, and (d) synthetic profile assuming a half spreading rate of $4.4 \mathrm{~cm} /$ year. Skewness of $160^{\circ}$, magnetization intensity of $2.5 \mathrm{~A} / \mathrm{m}$, and magnetized layer top depth of $6 \mathrm{~km}$ and thickness of $1 \mathrm{~km}$ were assumed. Geomagnetic polarity timescale of Gradstein et al. (2004) is used. Color scale of the bathymetry is the same as Figure 2.

\section{Competing interests}

The authors declare that they have no competing interests.

\section{Authors' contributions}

TS and TY collected and analyzed the data, OI designed the YK10-14 cruise and provided information on radiometric ages, all contributed to the discussion, and TS and TY wrote the manuscript. All authors read and approved the manuscript.

\section{Acknowledgements}

We thank all onboard scientists, officers, and crew of the YK10-14 cruise of RN Yokosuka for the cooperation. We also thank Hiromi Fujimoto of Tohoku University for making us available for the ring laser gyro and Nobukazu Seama of Kobe University for the three-component magnetometer during the YK10-14 cruise. The manuscript was greatly improved by constructive comments of two anonymous reviewers. This research was supported by a Grant-in-Aid for Scientific Research ((C) No. 22540473) from the Japan Society for the Promotion of Science. The GMT software (Wessel and Smith 1995) was used for processing the data and producing the figures.

\section{Author details}

${ }^{1}$ Graduate School of Life and Environmental Sciences, University of Tsukuba, 1-1-1 Tennodai, Tsukuba, Ibaraki 305-8572, Japan. ${ }^{2}$ Geological Survey of Japan, AIST, 1-1-1 Higashi, Tsukuba, Ibaraki 305-8567, Japan. ${ }^{3}$ Atmosphere and Ocean Research Institute, University of Tokyo, 5-1-5 Kashiwanoha, Kashiwa, Chiba 277-8564, Japan.

Received: 7 April 2014 Accepted: 29 July 2014

Published: 4 August 2014

\section{References}

Andrews JE (1980) Morphologic evidence for reorientation of sea-floor spreading in the West Philippine Basin. Geology 8:140-143

Deschamps A, Lallemand S (2002) The West Philippine Basin: an Eocene to early Oligocene back arc basin opened between two opposed subduction zones. J Geophys Res 107:2322, doi:10.1029/2001JB001706

Deschamps A, Okino K, Fujioka K (2002) Late amagmatic extension along the central and eastern segments of the West Philippine Basin fossil spreading axis. Earth Planet Sic Lett 203:277-293

Deschamps A, Shinjo R, Matsumoto T, Lee CS, Lallemand SE, Wu S, Scientific party of KR03-04 and KR04-14 cruises (2008) Propagators and ridge jumps in a back-arc basin, the West Philippine Basin. Terra Nova 20:327-332

Fujioka K, Okino K, Kanamatsu T, Ohara Y, Ishizuka O, Haraguchi S, Ishii T (1999) Enigmatic extinct spreading center in the West Philippine backarc basin unveiled. Geology 27:1135-1138

Gradstein FM, Ogg JG, Smith AG (2004) A geologic time scale 2004. Cambridge University Press, Cambridge, p 589

Hall R (2002) Cenozoic geological and plate tectonic evolution of SE Asia and the SW Pacific: computer-based reconstructions, model and animations. J Asian Earth Sci 20:353-431
Hall R, Fuller M, Ali JR, Anderson CD (1995) The Philippine Sea Plate: magnetism and reconstruction. AGU Monogr 88:371-404

Hess HH (1948) Major structural features of the western north Pacific, and interpretation of H.O. 5989 bathymetric chart, Korea to New Guinea. Geol Soc Am Bull 59:417-446

Hilde TWC, Lee C-S (1984) Origin and evolution of the West Philippine Basin: a new interpretation. Tectonophysics 102:85-104

Isezaki N (1986) A new shipboard three-component magnetometer. Geophysics 51:1992-1998

Ishizuka O, Taylor RN, Yuasa M, Ohara Y (2006a) Making and breaking an island arc: a new perspective from the Oligocene Kyushu-Palau arc, Philippine Sea. Geochem Geophys Geosyst 12, Q05005, doi:10.1029/2010GC003440

Ishizuka O, Kimura JI, Li YB, Stern RJ, Reagan MK, Taylor RN, Ohara Y, Bloomer SH, Ishii T, Hargrove US III, Haraguchi S (2006b) Early stages in the evolution of Izu-Bonin Arc volcanism: new age, chemical, and isotopic constraints. Earth Planet Sci Lett 250:385-401

Ishizuka O, Yuasa M, Taylor RN, Sakamoto I (2009) Two contrasting magmatic types coexist after the cessation of back-arc spreading. Chem Geol 266:274-296

Ishizuka O, Taylor RN, Ohara Y, Yuasa M (2013) Upwelling, rifting, and age-progressive magmatism from the Oki-Daito mantle plume. Geology 41:1011-1014

Karig DE (1975) Basin genesis in the Philippine Sea. Init Rept DSDP 31:857-879

Louden KE (1976) Magnetic anomalies in the West Philippine Basin. AGU Geophys Monogr 19:253-276

Mrozowski CLS, Lewis D, Hayes DE (1982) Complexities in the tectonic evolution of the West Philippine Basin. Tectonophysics 82:1-24

Okino K, Fujioka K (2003) The central basin spreading center in the Philippine Sea: structure of an extinct spreading center and implications for marginal basin formation. J Geophys Res 108:2040, doi:10.1029/2001JB001095

Park C-H, Tamaki K, Kobayashi K (1990) Age-depth correlation of the Philippines Sea back-arc basins and other marginal basins in the world. Tectonophysics 181:351-371

Sandwell DT, Smith WHF (1997) Marine gravity anomaly from Geosat and ERS 1 satellite altimetry. J Geophys Res 102:10039-10054

Sato T, Oda H, Ishizuka O, Arai K (2014) Detailed bathymetry and magnetic anomaly in the Central Ryukyu Arc, Japan: implications for a westward shift of the volcanic front after approximately 2.1 Ma. Earth Planets Space 66:68, doi:10.1186/1880-5981-66-68

Shih TC (1980) Marine magnetic anomalies from the western Philippine Sea: implications from the evolution of marginal basins, tectonic and geologic evolution of southeast Asia seas and islands. AGU Geophys Monogr 23:49-75

Seama N, Nogi Y, Isezaki N (1993) A new method for precise determination of the position and strike of magnetic boundaries using data of the geomagnetic anomaly field. Geophys J Int 113:155-164

Taylor B, Goodliffe AM (2004) The West Philippine Basin and the initiation of subduction revisited. Geophys Res Lett 31, L12602, doi:10.1029/2004GL020136

Uyeda S, Ben-Avraham Z (1972) Origin and development of the Philippine Sea. Nature 240:176-178

Wessel P, Smith WHF (1995) New version of the generic mapping tools released. Eos Trans 76:329

\section{doi:10.1186/1880-5981-66-83}

Cite this article as: Sasaki et al: A revised spreading model of the West

Philippine Basin. Earth, Planets and Space 2014 66:83.

\section{Submit your manuscript to a SpringerOpen ${ }^{\odot}$ journal and benefit from:}

- Convenient online submission

- Rigorous peer review

- Immediate publication on acceptance

- Open access: articles freely available online

- High visibility within the field

- Retaining the copyright to your article

Submit your next manuscript at $>$ springeropen.com 